\title{
Enhanced Renewable Energy Adoption for Sustainable Development in India: Interpretive Structural Modeling Approach
}

\author{
Vimal Kumar Eswarlal ${ }^{1 *}$, Prasanta Kumar Dey ${ }^{1}$, Ravi Shankar ${ }^{2}$ \\ ${ }^{1}$ Aston University, Birmingham, United Kingdom \\ ${ }^{2}$ Indian Institute of Technology Delhi, New Delhi, India \\ *Corresponding author.Tel: +44 7843946797,E-mail: vimaleswarlal@yahoo.com / eswarlvk@aston.ac.uk
}

\begin{abstract}
Poverty alleviation and social upliftment of rural India is closely linked with the availability and use of energy for development. At the same time, sustainable supply of clean and affordable renewable energy sources is required if development is to be sustainable, so that it does not cause any environmental problems. The purpose of this paper is to determine the key variables of renewable energy implementation for sustainable development, on which the top management should focus. In this paper, an interpretive structural modeling (ISM) - based approach has been employed to model the implementation variables of renewable energy for sustainable development. These variables have been categorized under 'enablers' that help to increase the implementation of renewable energy for sustainable development. A major finding of this research is that public awareness regarding renewable energy for sustainable development is a very significant enabler. In this paper, an interpretation of variables of renewable energy for sustainable development in terms of their driving and dependence powers has been examined. For better results, top management should focus on improving the highdriving power enablers such as leadership, strategic planning, public awareness, top management support, availability of finance, government support, and support from interest groups.
\end{abstract}

Keywords: Sustainable development, Renewable energy, Performance measures, Interpretive structural model, India

\section{General structure of the paper}

The world energy forum has pointed out that coal and gas reserves will become depleted in less than the next 10 decades. Ashwani Kumar et al, [1] observed that fossil fuels account for around $79 \%$ of the energy consumption in the world, and $57.7 \%$ is consumed by the transport sector and is being depleted very speedily. Apart from this, various environmental problems are also related with the increasing use of fossil based oils, coal and gas. So there is an urgent need to develop the alternative energy resources in order to overcome the future energy shortage. Also, the depletion of natural resources and increasing demand of energy nowadays has forced policymakers to consider alternative energy sources for sustainable development. 'Sustainable development' means development which is capable of being sustained for the future stability. Where, renewable energy sources are regenerative and do not get exhausted. Renewable energy helps the world in reducing their carbon emission and cleans up the air and helps in achieving sustainable development. The most important feature of renewable energy sources is their environmental suitability but sustainable development does not only revolve around the environmental stability but it a lso deals with social and economical stability. Hence, nowadays investigation of energy strategies for renewable energy has become crucial, particularly for the stability of future energy.

India's population has been increasing very rapidly and it is also the fastest growing economy in world (with GDP of \$ 1 trillion measured in 2008) after china, which further leads to a hike in energy demand and its impact on the environment in India. Mohit Goyal et al, [2] pointed out that India's power sector has shown tremendous increase from $30,000 \mathrm{M} \mathrm{W}$ in 1981 to 143,000 MW by March 2008. As the fossil fuels are depleting fast, India will face the energy shortages in future which need to be addressed by developing alternative energy resources the country can rely on. India is left with no option but to concentrate towards the maximum use 
of renewable energy. Fortunately India has plenty of renewable resources such as wind energy, biomass energy, small hydro power and solar energy to exploit for sustainable development. India is set to reach the aim of producing $10 \%$ of total power supplied through renewable energy by 2012 [1]. The government of India has promoted the use of renewable energy for sustainable development through several policy and provision interventions. Since 2007 power generation from renewable wind energy has increased by 3,857 MW; small hydro has increased by 619.53; biomass has increased by $322 \mathrm{MW}$; solar energy has increased by 8.10 MW and industrial and urban waste to energy has increased by $20.10 \mathrm{MW}$. Investment of around 3.9 billion Indian rupees ( $\$ 86$ million) has been made for different renewable energy projects and programs. Meanwhile, the World Bank has also allotted $\$ 4$ billion in loans for India's renewable energy projects.

The purpose of this paper is to search the variables affecting the progress of the renewable energy for the sustainable development in India. Policy makers would face many difficulties in implementing renewable energy for sustainable development due to various variables affecting its performance. These variables not only affect the performance of renewable energy development but also act upon e ach other. Hence, the methodology of Interpretive Structural Modeling (ISM) has been applied in this paper to establish the conceptual relationship amongst various variables which are hindering the path of renewable energy for the sustainable development.

\section{Literature review}

A lot of research has been done before to find out the variables which affect the implementation of the renewable energy for the sustainable development. Fred Beck et al, [3] have observed the main barriers to renewable energy development in 2004. McCormic et al, [4] observed the major barriers that affect the implementation of energy for the sustainable development on the basis of research conducted by Bioenergy network of excellence. Himri et al, [5] has worked on formulating barriers which are hindering the full potential and advantages of the renewable. Lidula et al, [6] has formulated the barriers for clean and sustainable energy in the ASEAN member countries. Mayfield et al, [7] has developed a new methodology to deal with the barriers affecting the performance of Biomass operations. Sharma et al, [8] has studied the parameters of waste management in India. New York State Energy Research and Development Authority and Oak Ridge National Laboratory (ORNL) have identified some of the barriers to energy through research [9].

An important barrier for renewable energy development is lack of leadership qualities in managers. A good strategic plan identifies the renewable energy goals and then formulates policies to achieve these goals. Sustainable energy development strategies should deal with energy saving, improvement in the efficiency of energy production and replacement of the fossils based oils, coal and gas reserves [10]. There are two major factors which have affected the energy pattern most; the technological changes and the availability of energy resources [11]. Renewable sources are present in abundance but still cannot be harnessed for sustainable development due to lack of technology and public awareness. Continuing innovation in technology is necessary to harness each form of renewable energy [12]. The major challenge for the renewable energy industry is the timely availability of resources [10]. Himri et al, [5] has pointed out that lack of information dissemination would lead to lack of support from different stake holders. So, the availability of data and information acts as an enabler for the renewable energy for the sustainable development. The shortage of skilled professionals which includes designers, installers, service and sales representatives, policy analysts, scientists, engineers, teachers and researchers can also affect the quality of the system [13]. 
Government has put lots of effort towards enhancing the use of renewable energy for the sustainable development through subsidies, fiscal incentives and has encouraged investors to invest in renewable energy through various relevant supportive policies. Moreover, huge amount of investment is needed in developing the advanced technology required to fully exploit some renewable resources. Due to longer investment periods the risk of return on investment is high [14]. Hence it is necessary to incorporate the relevant policies in order to attract the interest groups to invest in it. The market for renewable energy has increased significantly and manufacturers are investing huge amount of money in R\&D (research and development) of RET (renewable energy technology) which will further lead to economically sustainable growth. Table 1 below shows the 14 variables chosen based on the previous research.

Table 1. Variables affecting the performance of renewable energy for sustainable development

\begin{tabular}{ll}
\hline S. No. & Variables \\
\hline 1. & Leadership \\
2. & Strategic planning \\
3. & Availability of technology \\
4. & Public awareness \\
5. & Top management support \\
6. & Sustainable growth \\
7. & Return on investment \\
8. & Availability of finance \\
9. & Skilled man power \\
10. & Government support \\
11. & Availability of data and information \\
12. & Availability of energy resources \\
13. & Support from interested groups (stake holders) \\
14. & Efficiency of process and execution \\
\hline
\end{tabular}

\section{Methodology}

Interpretive structural modeling is a tool which here is applied for the analysis of the interaction amongst variables of the renewable energy for sustainable development. This approach has been used in many fields by scholars to investigate the inter-relationship amongst many variables. Warfield, [15] is the one who has introduced interpretive structural modeling (ISM) and Malone, [16] is the second one who conducted brief review of the ISM. It provides us means by which order can be imposed on the complexity of such elements [17, 18]. This method is known as 'interpretive structural modeling' because all the variables and their interrelationships are decided by group judgment. The ISM methodology is an interactive learning process in which a s et of different and directly or indirectly related elements affecting the system under consideration is structured into a comprehensive systemic model [9]. Finally the graphical representation of the relationships among the variables is demonstrated. This methodology (ISM) has attracted a great deal of interest recently due to its high flexibility. Following are the steps involved in the formulation of ISM:

1.The variables affecting the performance of the system are listed with the help of literature review and expert opinion.

2.A conceptual relationship amongst the variables is made by the help of opinion of the experts.

3.Then a structural self-interaction matrix (SSIM) is formulated which entails the pair wise relation of the variables. 
4.Now, the reach ability matrix is derived from the structural self interaction matrix (SSIM) by putting ' 1 ' and ' 0 ' which shows pair wise relationship accordingly.

5.Then the transitivity is removed from the reach ability matrix and transitivity rule says that if variable ' $A$ ' leads to variable ' $B$ ' and ' $B$ ' leads to variable ' $C$ ' then ' $A$ ' will also lead to variable ' $\mathrm{C}$ '.

6. The reachability matrix is divided into different partition levels.

7.The directed graph is drawn on the basis of the relationship between the variables discussed in the above reachability matrix and all the transitive links are removed.

8. The digraph is converted into ISM by converting variables nodes in to statements.

9. Finally a review of the ISM model is done and any necessary modifications are carried out.

After the final ISM structure MICMAC analysis of the variables is done on the basis of their driving and dependence power. MICMAC was first proposed by Duperrin and Godet in 1973 [19]. MICMAC analysis can be used to categorize variables in a co mplicated system [20]. The prime function of MICMAC analysis is to examine the driving and dependence power of the variables $[17,18]$. Here the barriers are divided into four classifications according to their driving and dependence power known as autonomous, linkage, dependent and independent barriers [18]. The first cluster is known as 'autonomous barriers' which have very weak driving power and simultaneously have weak dependence power. These variables mostly have no connection with the system or with other variables; they only share few links which can be strong. The second cluster is known as 'dependent barriers' which consist of variables having weak driving power and strong dependence power. These variables mostly depend on other variables so; any action on other variables will affect the dependent variables. The third cluster consists of the 'linkage variables' which have strong driving and strong dependence power. These variables are highly unstable so, any action on these variables will affect other variables and also have a feedback effect on the linkage variable. Lastly the fourth cluster is basically the 'independent barriers', consists of variables which have strong driving power and weak dependence power.

\section{Results}

The ranking of all variables is known through level partitions so they have been put at their respective levels in the ISM hierarchy. Interpretive structural model is finally formulated with the help of final reach ability matrix and level partitions, which is shown in Fig. 1. It is observed from the ISM based model that public awareness about renewable energy is a very important variable as it has highest driving power and zero dependence power. This means this variable is very significant and drives all other variables. So, the policy maker has to keep more focus on public awareness in order to implement renewable energy for the sustainable development successfully. Awareness about renewable energy among the public will lead to top management support (variable 5). Conversely leadership qualities of a manager (variable 1) can act as a tool only if there is a top management support. Good strategic planning (variable 2) needs manager leadership quality and incentive support from top management. Support from interested groups (variable 13) cannot exist if there are no top management support withinpolicy makers. Availability of finance (variable 8) is ensured by support from the interested groups (stakeholders). Skilled man power (variable 9) and availability of information is very necessary for the successful implementation of renewable energy projects for sustainable development. Availability of finance actually helps in achieving the skilled man power as skilled man power is highly costly. Information management (variable 11) ensures the effective utilization of the resources. 


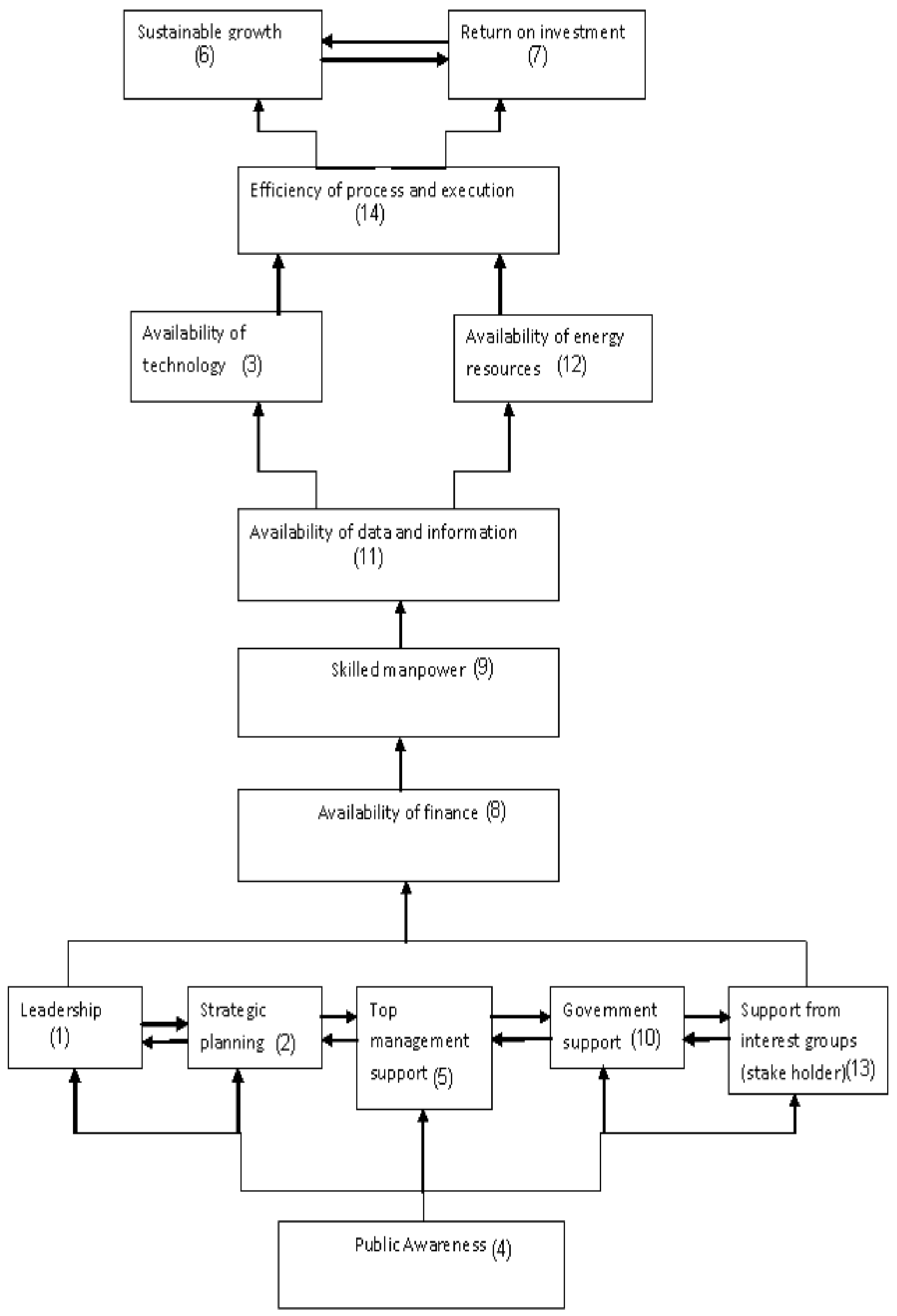

Fig. 1. ISM Based Model 
Lack of appropriate data and information will lead to lack of interest from public and management, which further leads to lack of energy resources (variable 12) and lack of renewable energy technology (variable 3). Outdated technology has a direct impact on the efficiency of the process and its execution (variable 14). So, more and more money should be invested in the development of new technologies for the successful implementation of the renewable energy projects. High efficiency of the process will lead to sustainable growth (variable 6), which further leads to return on i nvestment (variable 7) or vice versa. Good return on investment is a symbol of an economically sustainable system. This study shows that all the above discussed variables are enablers which enable the successful implementation of the project. According to ISM hierarchy there is a great need to work upon these variables for the sustainable development through renewable energy sources.

The MICMAC analysis has been drawn as shown in Fig. 2 below, the driving and dependence power has been shown in final reachability matrix. In the MICMAC diagram below the column and rows represent the driving and dependence power respectively. All the variables have been placed in the diagram according to their driving and dependence power. As an example variable 4 (public awareness) has driving power of 14 and dependence power of 1 and therefore has been placed accordingly in the MICMAC diagram at the extreme top left of the diagram.

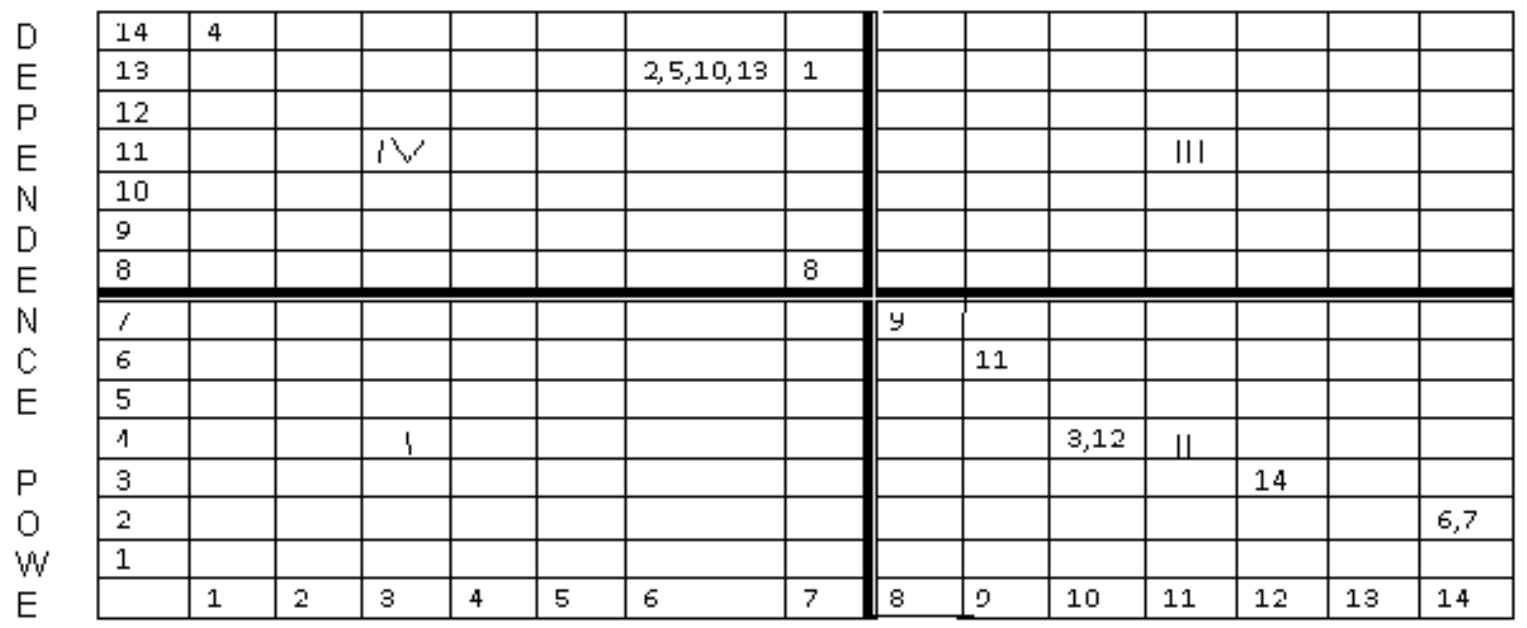

$\mathrm{R}$

DRIVING POWER

Fig. 2. MICMAC Diagram

\section{Discussion and Conclusion}

India is growing very fast approximately at a rate of $9 \%$ and the situation of energy shortage gets darker with the increase in the economic growth of the country. India has to exploit all sources of renewable energy in order to tackle the energy shortage problem [2]. The only solution remaining to the policy makers is using renewable energy as fossil based oils, coal and gas reserves are at the verge of depletion. But there are lots of variables which affect the implementation of renewable energy for sustainable development. Policy makers therefore face lots of challenges in identifying these variables and then working upon them to improve the performance of the system. Some variables termed as 'enablers' have been identified in this paper and interrelationships among these variables have been formulated using ISM methodology. This provides the hierarchy of action which has to be performed by the policy makers in order to improve the efficiency of the system. 
From ISM based model (drawn above) it can be concluded that variable 4 (public awareness) is of top most priority as it has highest driving power of 14 and lowest dependence power of 1. This also states that policy makers have to create public awareness about the use of renewable energy for the sustainable development. In MICMAC analysis this has been concluded that there are no autonomous variables which prove that all variables stated above influence the implementation of the renewable energy for the sustainable development. Similarly from the MICMAC analysis it has also been concluded that there are no variables in the third cluster which is linkage barriers. This shows that all the variables stated above are stable. From the diagram it has been observed that variables such as leadership, strategic planning, public awareness, top management support, availability of finance, government support, and support from interest groups (stakeholders) fall under the fourth cluster which is 'independent barriers'. All these variables have high driving power and policy makers should focus more on these variables as they affect or influence other enabling variables. Availability of technology, availability of data and information, sustainable growth, return on investment, skilled manpower, availability of energy resources and efficiency of processes are those variables which fall under second cluster (dependent barrier) and have high dependence power.

Basically ISM based model in Fig.1, represents an overall picture of the problems in implementing renewable energy for the sustainable development in front of the policy makers. This research has most importantly identified the variable affecting the performance of the process and interrelationship among them. This model works for the better managerial decisions in order to have more efficient and effective renewable energy project for sustainable development. Also this work identifies leadership, strategic planning, public awareness, top management support, availability of finance, government support, and support from interest groups (stake holders) as very important factors, which needs immediate and high attention from the policy makers.

In this research work, interrelationship among the variables of implementation of renewable energy for sustainable development has been formulated, but it has to be mentioned that this model is not statistically validated. SEM (Structural equation modeling) sometimes also referred as linear structural relationship approach acts as a tool in order to test the validity of such hypothetical models [18]. The scope for future work following this research is to test the validity of this hypothetical model i.e. ISM using SEM.

\section{References}

[1] A. Kumar, K. Kumar, N. Kaushik, S. Sharma and S. Mishra, Renewable energy in India: current status and future potentials, Renewable and Sustainable Energy Reviews 14, 2010, pp. 2434 - 2442

[2] M. Goyal and R. Jha, Introduction of Renewable Energy Certificate in the Indian scenario, Renewable and Sustainable Energy Reviews 13, 2009, pp. 1395 - 1405

[3] F. Beck and E.Martinot, Renewable Energy Policies and Barriers, Chapter of the Book: C. J. Cleveland, and R.U. Ayres (Ed.), Encyclopedia of Energy, Elsevier Academic Press, 2004.

[4] K. McCormick and T. Ka berger, Key barriers for bioenergy in Europe: economic conditions, know-how and institutional capacity, and supply chain co-ordination, Biomass and Bioenergy 31, 2007, pp. 443 - 452. 
[5] Y. Himri, A. S. Malik, A. B. Stambouli, S. Himri and B. Draoui, Review and use of the Algerian renewable energy for sustainable development, Renewable and Sustainable Energy Reviews 13, 2009, pp. 1584 - 1591.

[6] N.W.A. Lidula, N. Mithulananthan, W. Ongsakul, C. Widjaya and R. Henson, ASEAN towards clean and sustainable energy: potentials, utilization and barriers, Renewable Energy 32 (9), 2007, pp. 1441 - 1452.

[7] C. Mayfield, C.D. Foster, C.T. Smith, J. Gan, and S. Fox, Opportunities, barriers, and strategies for forest bioenergy and bio-based product development in the Southern United States, Biomass and Bioenergy 31, 2007, pp. 631 - 637.

[8] H.D. Sharma, A.D. Gupta, and A. Sushil, The objectives of waste management in India: a futures inquiry, Technological Forecasting and Social Changes 48, 1995, pp. 285 - 309.

[9] B. Tonn, and J.H. Peretz, State-level benefits of energy efficiency, Energy Policy 35, 2007 , pp. $3665-3674$.

[10] H. Lund, Renewable energy strategies for sustainable development, Energy 32, 2007, pp. 912 - 919.

[11] N.H. Afgan, D.A. Gobaisi, M.G. Carvalho and M. Cumo, Sustainable energy development, Renewable and Sustainable Energy Reviews 2, 1998, pp. 235 - 286.

[12] B.S.K. Naidu, Indian scenario of renewable energy for sustainable development, Energy policy 24 (6), 1996, pp. 575 - 581.

[13] P. Jennings, New directions in renewable energy education, Renewable Energy 34, 2009, pp. $435-439$.

[14] G.H. Wanga, Y. X. Wangb, and T. Zhaoa, Analysis of interactions among the barriers to energy saving in China, Energy Policy 36, 2008, pp. $1879-1889$.

[15] J.W. Warfield, Developing interconnected matrices in structural modeling, IEEE Transactions on Systems, Man and Cybernetics 4 (1), pp. 51 - 81.

[16] D.W. Malone, An introduction to the application of interpretive structural modeling, IEEE 63 (3), 1975, pp. 397-404.

[17] A. Mandal and S.G. Deshmukh, Vendor selection using interpretive structural modeling (ISM), International Journal Operations and Production Management 14 (6), 1994, pp. 52 $-59$.

[18] S. Jharkharia and R. Shankar, IT-enablement of supply chains: understanding the barriers, The Journal of Enterprise Information Management 18 (1), 2005, pp. 11 - 27.

[19] J.C. Duperrin and M. Godet, Methode De Hierar Chization Des Elements D'um System, Proceedings of Rapport Economique De CEA, Paris, 1973, pp. 45 - 51.

[20] J.W. Warfield, A science of generic design: managing complexity through systems design: volume 1, Intersystems Publications, Salinas, CA, 1990. 